\title{
Medical devices that should be prescribed to patients with cataplexy to reduce their risk of injury
}

Dr. Carolina Diamandis ${ }^{1}$ and Adrian Tudor ${ }^{2}$

${ }^{1}$ Affiliation not available

${ }^{2}$ LCG Greece

May 20, 2021

\begin{abstract}
People who suffer from cataplexy have a significant risk of injury. This paper discusses (manufacturer-independent) medical devices that should be prescribed to any patient with moderate to severe cataplexy.
\end{abstract}

\section{Hosted file}

Cataplexy aids for adults.pdf available at https://authorea.com/users/410930/articles/522786medical-devices-that-should-be-prescribed-to-patients-with-cataplexy-to-reduce-theirrisk-of-injury 